\title{
'Twas on a Monday morning...
}

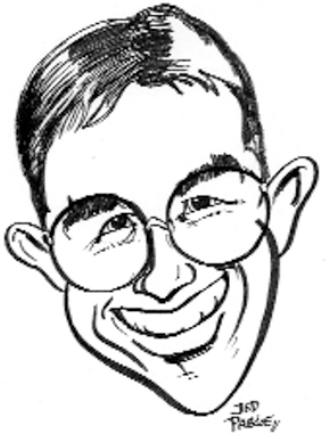

\section{S Hancocks, OBE*}

\section{The famous lyrics of the Flanders and Swan song echoed round the practice as} we decided to try and make some changes

'Twas on the Monday morning when the business consultant came to call. The starting point had been a decision to move the practice firmly into the 21st century, to meet head-on the challenges of the new competitive world of consumerism, patient-centred delivery of oral care and modern administration methods. Arriving in a neatly ironed polo-style shirt and carrying an impressive looking portfolio of management books, the young man in question strode into the reception area talking the while in an animated fashion into his mobile phone. "Sorry about that," he smiled apologetically, "bit of an on-going human resources crisis in one of our up-scaling franchises." We smiled back, wishing we could have smiled back knowingly.

Pointedly turning his mobile off, but reassuring us that there was a voice mail service and emergency action line number should we, or any of his other client base intimates need him urgently, he settled into the comfiest chair in the staff room and began. For someone who professed to be client-based-intimate-centred, his attitude seemed a little, well, sneery. Especially considering the fact that his hourly rate was about one and a half times that which he later suggested the practice adopted. What was our proposed business objectification ratio? To what extent did our current turnover reflect a desire to enhance the lifemission of our practice profile? Had we thought about the normative needs of the business in relation to the person specifications of the staff already employed? No one liked to say anything much except that mostly we just did fillings, crowns and veneers and tried to listen to what our patients had to say. He interacted with his mobile phone all the way back across the car park and drove off intending to integrate his on-site findings with our future consequence analysis breakdown.

'Twas on the Tuesday morning that the PR lady came to call. She was in, what we later discovered to be called "the fluffystoic' area of the proactive marketing spec- trum. She seemed pleasant just the same. Samples of marketing schemes tumbled out across the desk from her snake-skin effect attaché ensemble carrier (clearly marked 'snake-skin effect only - no venomous snakes were harmed in the crafting of this product') so that, she reassured us, she wasn't sending out 'brittle-driving' messages to potential customers for whom environmentally-friendly acts were paramount. In the brief times open to us while she drew breaths we managed to ask if she thought targeting mothers with young children was a good thing. Apparently it depended on what we meant exactly by 'good' and 'thing' and whether these were to be seen in the context of an on-going scheme and for what duration of activation since, by definition, every young family soon became an age-sensitive nuclear consumer unit with its own internal identity parameters. In the absence of our having the facilities to make her a cafè latte, we brewed up the best 'fluffy-stoic' instant coffee we could and she seemed to leave happy at least. mined not to be phased by this new modernism we sat in rapt attention. Apparently our façade was quite 'choppy' in terms of 'music' and in danger of creating a dead zone which risked being quite 'unloved'. The main corridor whilst being 'boulevard rather than street' should not miss the opportunity to be maximally interactive in terms of a heritage-based vibrancy. Creating more of a sense of presence without being aggressive should be the objective of the reception area in which all comers to the practice should be enabled to 'land in the same point'. For the surgeries a side-on option was the rescaling of the potential 'commotion zone' albeit it in a reduced form. From which we thought he meant that they would be smaller but just look bigger. The main puzzle was that he never mentioned the dark room, for which we'd been trying to find another place for ages.

'Twas on the Friday morning that the printer came to call. He said that he could take some pictures of the outside of the practice through a special lens that would

\section{For someone who professed to be client-based-intimate- centred, his attitude seemed a little, well, sneery.}

'Twas on the Wednesday morning that the designer called to reschedule as she was embroiled in a terrible trauma over fabric deliveries from Thailand since the silk as ordered was now failing to fraternise with the equinoxinal tones of the Lombardi marble entrance ambiance. We understood. Well, we understood that she wanted another appointment and said that we'd get back to her.

'Twas on the Thursday morning that the architect came to call. In fairness he had had a head start since this was his second, and reconnaissance-feedback report session. Clearly the modern way of architecture is not plans-upward based and we discovered that it would have been naïve of us to have expected such a linear conception articulation of the enterprise at this stage. Deter- make it look much better and airbrush the staff pictures that we showed him. If we could come up with some text he could have a sample leaflet with us in a couple of days and, once approved, a quantity of how ever many thousands we wanted by later that week. We provisionally ordered five thousand and said we thought blue was a good colour to kick-off with.

'Twas on the following Monday morning that we started calling prosthodontics dentures, periodontitis - gum disease and caries - decay. You see, 'twas on that Monday morning that patients started to understand what on earth we were talking about and why it was we cared for them.

\section{* Stephen Hancocks is Commissioning Editor of the BDJ}

